\title{
Listeria monocytogenes infection in a prosthetic knee joint in rheumatoid arthritis
}

\author{
Linda V Booth, M T Walters, A C Tuck, R A Luqmani, M I D Cawley
}

\begin{abstract}
The prosthetic knee joint of a 64 year old woman with severe rheumatoid arthritis was found to be infected with Listeria monocytogenes. After treatment with intravenous antibiotics, symptoms gradually resolved. She subsequently received prolonged treatment with oral co-trimoxazole and 18 months later remained well.
\end{abstract}

Listeriosis is an uncommon cause of joint infection in rheumatology despite its predilection for the immunocompromised host. Listeria monocytogenes causes neonatal infections, septicaemia (resulting in a flu-like illness in pregnancy), and meningoencephalitis. There have been reports of listeria septic arthritis ${ }^{1-3}$ and two cases of infected prosthetic joints. ${ }^{4}$ No cases of listeria joint infection were found in a previous survey of non-prosthetic bacterial arthritis from this hospital. ${ }^{6}$

\section{Case report}

A 64 year old woman with a 25 year history of severe seropositive, erosive, deforming rheumatoid arthritis and cryptogenic hepatic cirrhosis of recent onset had previously undergone numerous surgical procedures, including a right Freeman Swanson knee arthroplasty (1979), left total knee replacement, and bilateral total hip replacements.

Drug treatment included gold and oral corticosteroids until 1976 and penicillamine and azathioprine until mid-1986. Phenylbutazone, given from the onset of her disease, was stopped in January 1987 after hospital admission for pneumonia and gastrointestinal bleeding, subsequently complicated by pseudomembranous enterocolitis induced by cefotaxime. A small, asymptomatic effusion in the right prosthetic knee joint was noted before discharge on ibuprofen and ranitidine treatment.

By May 1987 she had developed pain and a large effusion in the right prosthetic knee joint. Other joints showed multiple rheumatoid deformities, but synovitis was generally inactive. She had no fever and was otherwise well. On investigation the following results were obtained: haemoglobin $117 \mathrm{~g} / \mathrm{l}$, white cell count $5.5 \times 10^{9} / 1$, platelets $337 \times 10^{9} / 1$, erythrocyte sedimentation rate $82 \mathrm{~mm} / \mathrm{h}$, plasma electrolytes and renal function normal, alkaline phosphatase greater than 1500 IU/1 (normal 100-300 IU/l), aspartate aminotransferase 48 IU/1 (normal 5-42 IU/l). Blood cultures were sterile. Bloodstained purulent synovial fluid (10 $\mathrm{ml}$ ) aspirated from the right knee contained Gram positive rods. After 48 hours small nonhaemolytic colonies grew, which were sensitive on disc testing to ampicillin, erythromycin, gentamicin, and co-trimoxazole, but were moderately resistant to penicillin. Treatment of the patient (weight $45 \mathrm{~kg}$ ) was started with $1.5 \mathrm{~g}$ ampicillin intravenously four times a day. A knee aspiration three days later was sterile with scanty pus cells and ampicillin was continued. Minimal inhibitory concentrations of the isolate to ampicillin and penicillin were $0.03 \mathrm{mg} / \mathrm{l}$ and $0.25 \mathrm{mg} / \mathrm{l}$ respectively, thus showing acceptable sensitivity to penicillin. As it was desirable to use narrow spectrum treatment in a patient with recent pseudomembranous colitis, treatment was changed 16 days later to benzylpencillin $1 \cdot 2 \mathrm{~g}$ four times a day. On subculture, the organism displayed $\beta$ haemolysis and was identified as Listeria monocytogenes serotype 1.

Both ampicillin and penicillin are active against listeria, but consideration of successful treatment given for serious listeria infections ${ }^{7}$ prompted treatment with intravenous ampicillin $1.5 \mathrm{~g}$ four times a day and gentamicin. Two further aspirations were performed during this treatment and both were sterile. Serum and synovial fluid concentrations of ampicillin three hours after the dose were both $40 \mathrm{mg} / \mathrm{l}$, showing excellent joint penetration, as we would expect from previous studies, ${ }^{8}$ and both samples gave bactericidal titres of 1/256 against the patient's own organism.

Serum antibodies to Listeria monocytogenes serotype 1 were undetectable one month after the positive culture. The patient completed six weeks' treatment with ampicillin and gentamicin intravenously, giving a total duration of 10 weeks' parenteral treatment. She was gradually mobilised and discharged on oral co-trimoxazole ( $960 \mathrm{mg}$ twice daily), which she was still receiving 18 months later having remained well.

\section{Discussion}

Natural joint infections with listeria have been reported in one diabetic patient (ankle infected) ${ }^{2}$ and two rheumatoid patients ${ }^{13}$ (both with infected knee joints after treatment with intraarticular corticosteroids and yttrium-90 silicate in one case $\left.^{3}\right)$. Prosthetic hip joint infections
Correspondence to: Dr Booth. 
have been reported in a patient with degenerative osteoarthritis ${ }^{5}$ and in a patient receiving long term steroids after renal transplant. ${ }^{4}$

Blood cultures were positive in two ${ }^{24}$ of the five patients with positive joint cultures. Our case and four of the previously reported cases showed no preceding systemic symptoms, though it is conceivable that our patient's earlier hospital admission might have been complicated by unrecognised listeriosis with subsequent dormant infection in the prosthesis. The absence of systemic listeria antibodies may reflect the protected site of the organism. Treatment of the natural joint infections varied and included cefoxitin, ${ }^{2}$ and ampicillin with chloramphenicol joint irrigation. ${ }^{3}$ The remaining case failed to respond to cephalothin and gentamicin, required joint drainage and irrigation, and ultimately responded to ampicillin and gentamicin. ${ }^{1}$

One prosthetic joint infection was treated with intravenous ampicillin followed by lifelong oral amoxycillin. ${ }^{4}$ Management of the other infected prosthesis included surgical removal, followed by parenteral ampicillin with tobramycin, then ampicillin alone followed by oral co-trimoxazole for three months, and, finally, reimplantation of a new prosthesis. ${ }^{5}$

During the initial management of our patient there were no previously recorded cases of prosthetic joint infection and hence prolonged parenteral antibiotic treatment was given in a manner analogous to the treatment of listeria endocarditis ${ }^{7}$ (a condition known to require effective bactericidal treatment). Surgical options for the infected prosthesis were considered to be extremely limited and thus antibiotics offered the only chance of salvaging joint function. We are uncertain whether to give oral co-trimoxazole indefinitely. As it is well tolerated there is little to gain by discontinuing it and risking a relapse. In addition, our patient fulfils the clinical and microbiological criteria which have been proposed as indicating that lifelong antibiotics may permit joint function to be retained. ${ }^{9}$

Listeria infections are reported to be increasing in the United Kingdom and there is currently concern over the microbiological safety of soft cheeses and cook-chill foods. Interestingly, our patient reported consuming unpasteurised milk in beverages on a farm. It remains to be seen if listeria infections will be found more often in future in the immunocompromised patients encountered in rheumatology practice.

1 Newman J H, Waycott S, Cooney Leo M Jr. Arthritis due to Listeria monocytogenes. Arthritis Rheum 1979; 22: 1139-40. 2 Breckenbridge R L Jr, Buck L, Tooley E, Douglas G W. Listeria monocytogenes septic arthritis. Am $\mathcal{F}$ Clin Pathol 1980; 73: 140-1. 3 Wilson A P R, Prouse P J, Gumpel J M. Listeria yttrium-90 therapy. Ann Rheum Dis 1984; 43: 518-9.

4 Abadie S M, Dalovisio J R, Pankey G A, Cortez L M. Listeria monocytogenes arthritis in a renal transplant recipient. F Infect Dis 1987; 156: 413

5 Arathoon E, Goodman S B, Vosti K L. Prosthetic hip infection caused by Listeria monocytogenes. F Infect Dis infection caused by

6 Cooper C, Cawley M I D. Bacterial arthritis in an English health district: a ten year review. Ann Rheum Dis 1986; 45: 458-63.

7 Sheinman B D, Evans T, Sage R. Listeria monocytogenes endocarditis. Postgrad Med $\mathcal{F}$ 1985; 61: 51-2.

8 Sattar M A, Barrett S P, Cawley M I D. Concentrations of some antibiotics in synovial fluid after oral administration, with special reference to antistaphylococcal activity. Ann Rheum Dis 1983; 42: 67-74.

9 Brause B D. Infected total knee replacement: diagnostic, therapeutic and prophylactic considerations. Orthop Clin North Am 1982; 13: 245-9. 